\title{
Alterações na bioquímica hepática em cães com leptospirose aguda determinada por amostras do sorogrupo Icterohaemorrhagiae
}

\author{
Hepatic biochemistry alterations in dogs with naturally occurring acute leptospirosis determined by \\ Icterohaemorrhagiae serogroup
}

\author{
Isabel Maria Alexandre Freire ${ }^{\mathrm{I}}$ Renato Varges $^{\mathrm{I}}$ Walter Lilenbaum $^{\mathrm{I}}$
}

\begin{abstract}
- NOTA-
RESUMO

Foram testadas 120 amostras séricas de cães com títulos $(\geq 100)$ perante Leptospira spp. serovar Icterohaemorrhagiae para a determinação da atividade sérica

when compared to the control group and also to the group of dogs with titres $<200(P<0.05)$. A clear correlation was observed between hepatic damage, without hepatocellular necrosis, and specific seroreactivity for leptospirosis caused by serogroup Icterohaemorrhagiae.
\end{abstract} de alanina aminotransferase (ALT), aspartato aminotransferase (AST), fosfatase alcalina (FA), gamaglutamiltransferase (GGT) e dos níveis séricos de colesterol total, triglicerídeos, proteína total, albumina, globulinas e bilirrubinas total, direta e indireta. Um grupo de 34 animais sem qualquer sintomatologia clínica e idade semelhante ao grupo testado foi utilizado como controle, tendo sido submetido às mesmas dosagens bioquímicas. Os animais com títulos $\geq 200$ apresentaram dosagens de FA e bilirubina direta superiores ao grupo controle e também aos animais com títulos menores que $200(P<0,05)$. Observou-se uma clara correlação entre dano hepático, sem necrose hepatocelular, com a sororeatividade específica para leptospirose, em animais acometidos de infecção por amostras do sorogrupo Icterohaemorrhagiae.

Palavras-chave: leptospirose, cães, Icterohaemorrhagiae, fígado.

\section{ABSTRACT}

One hundred and twenty serum samples obtained from dogs with specific titres $(\geq 100)$ against Leptospira spp. serovar Icterohaemorrhagiae were tested in order to determine the enzymatic activities of alanine aminotransferase ( $A L T)$, aspartate aminotransferase (AST), alkaline phosphatase (ALP), gamaglutamyltransferase (GGT), as well as of the total cholesterol, triglycerides, total protein, albumin, globulins and total, direct and indirect bilirubins serum concentrations. Thirty four animals free from clinical signs with the same age of the tested group were used as control group and submitted to the same biochemical tests. The animals with titres $\geq 200$ showed increased ALP activity and greater direct bilirubin concentration
Key words: leptospirosis, dogs, Icterohaemorrhagiae, liver.

A leptospirose é uma doença infecciosa de distribuição mundial, sendo uma zoonose importante e bastante freqüente em países em desenvolvimento. O agente etiológico da doença é a espiroqueta Leptospira interrogans com seus diversos serovares (FAINE et al., 2000). Os serovares Icterohaemorrhagiae, Copenhageni e Canicola são os mais freqüentes em caninos na região Sudeste do Brasil (FAVERO et al., 2002, FREIRE et al., 2007). Nesta espécie, a doença determina sinais clínicos bastante variados, manifestando-se desde uma forma aguda até as formas crônica e subclínica (HAGIWARA et al., 2004). A infecção por Icterohaemorrhagiae, que tem como reservatórios primários os roedores, determina doença aguda e severa, com comprometimento renal e hepático (GREENE et al., 2006).

Testes bioquímicos que demonstrem o grau de comprometimento hepático e renal associado aos dados sorológicos permitem uma caracterização mais rápida do quadro clínico, facilitando tanto o diagnóstico da enfermidade quanto o prognóstico dos animais (HAGIWARA et al., 2004). Apesar de as

'Laboratório de Bacteriologia Veterinária, Departamento de Microbiologia e Parasitologia, Universidade Federal Fluminense (UFF), Niterói, RJ, Brasil. Rua Hernani Mello, 101, 24210-130, Niterói, RJ, Brasil. E-mail: mipwalt@vm.uff.br. *Autor para correspondência. 
alterações pertinentes à função renal, notadamente as dosagens de uréia e creatinina, se encontrarem bem estabelecidas (NAVARRO et al., 1981; LILENBAUM et al., 1997, FREIRE et al., 2008), o estudo dos parâmetros bioquímicos hepáticos no cão com leptospirose e sua relação com os títulos de anticorpos específicos não está bem estabelecida. O objetivo do presente estudo foi descrever as alterações nos parâmetros bioquímicos hepáticos em cães clinicamente suspeitos de leptospirose aguda determinada pela amostra Icterohaemorrhagiae e relacionar estes achados com os títulos de anticorpos específicos.

Foram analisadas 120 amostras séricas de cães com sinais clínicos sugestivos de leptospirose aguda, caracterizada principalmente por icterícia, febre, petéquias e inapetência, provenientes da cidade do Rio de Janeiro e adjacências no período de março a novembro de 2004. Informações sobre a gravidade do estado clínico, realização do tratamento e recuperação dos animais foram fornecidas pelo médico veterinário clínico. Todas as amostras foram testadas pelo teste de soroaglutinação microscópica com antígenos vivos, conforme recomendação da OMS (FAINE et al., 2000). Um grupo de 34 animais sem qualquer sintomatologia clínica e idade semelhante ao grupo testado foi utilizado como controle, tendo sido submetido às mesmas dosagens bioquímicas.

As amostras selecionadas foram encaminhadas para determinação da atividade sérica de alanina aminotransferase (ALT), aspartato aminotransferase (AST), fosfatase alcalina (FA), gamaglutamiltransferase (GGT), e dos valores séricos de colesterol total, triglicerídeos, proteína total, albumina, globulinas e bilirrubinas total, direta e indireta. Para tal, utilizou-se o aparelho de bioquímica automatizado (Ciba Express $550^{\circledR}$ ) e reativos comerciais $\left(\right.$ Labtest $\left.^{\circledR}\right)$. O processamento das amostras foi realizado por método cinético enzimático, segundo as recomendações do fabricante. As variáveis quantitativas foram analisadas por meio do teste de Kruskal Wallis, com auxílio do software estatístico SPSS versão 12.0 (SPSS Inc, Chicago, EUA).

Dos 120 soros que apresentaram títulos perante amostras do sorogrupo Icterohaemorrhagiae, $88(73,3 \%)$ apresentaram títulos $=200$ e foram considerados positivos. Baseando-se nos títulos alcançados, os soros foram classificados em Grupo 1, ou fortemente reativos, com títulos $=800$ (25 animais 20,8\%), Grupo 2, ou reativos, com títulos entre 200 e 400 (63 animais - 52,5\%), e Grupo 3, ou negativos, com títulos $<200$ (32 animais - 26,7\%), conforme tabela 1 . Dados obtidos do grupo controle também podem ser verificados na tabela 1 .

Alterações significativas foram observadas nos parâmetros bioquímicos dos Grupos 1 e 2 (Tabela 1) quando os resultados foram comparados com os valores do grupo controle. Foram calculados os valores mínimo, máximo, média aritmética e desvio padrão dos três grupos de animais. Não houve diferença significativa entre os três grupos em relação aos parâmetros AST, ALT, GGT, colesterol total, triglicerídeos, proteína total, albumina, globulinas e bilirrubina indireta.

No entanto, diferença significativa entre os três grupos foi observada nos parâmetros FA e bilirrubina direta. O Grupo 1 apresentou valores de FA

Tabela 1 - Valores das dosagens de parâmetros bioquímicos hepáticos de cães com leptospirose aguda determinada por amostras do sorogrupo Icterohaemorrhagiae e animais sadios (grupo controle).

\begin{tabular}{|c|c|c|c|c|}
\hline Parâmetros bioquímicos & $\begin{array}{l}\text { Fortemente reativos } \\
\qquad(n=25)\end{array}$ & $\begin{array}{l}\text { Reativos } \\
(n=63)\end{array}$ & $\begin{array}{l}\text { Negativos } \\
(\mathrm{n}=32)\end{array}$ & $\begin{array}{l}\text { Grupo controle } \\
\qquad(\mathrm{n}=30)\end{array}$ \\
\hline & mín-máx (X×DP) & mín-máx (X×DP) & mín-máx (XさDP) & Mín-máx \\
\hline $\operatorname{AST}\left(\mathrm{U} \mathrm{L}^{-1}\right)$ & $22-2507(268,8 \pm 518,9)$ & $17-1808(221,5 \pm 327,7)$ & $20-847(125,7 \pm 153,2)$ & $20-87$ \\
\hline $\operatorname{ALT}\left(\mathrm{U} \mathrm{L}^{-1}\right)$ & $6-1334(179,9 \pm 280)$ & $10-5500(433,2 \pm 882,6)$ & $25-1426(223 \pm 354,5)$ & $13-72$ \\
\hline $\mathrm{FA}\left(\mathrm{U} \mathrm{L}^{-1}\right)$ & $26-2306(691,1 \pm 680)$ & $5-6440(646,4 \pm 1102,6)$ & $14-2178(297,7 \pm 440)$ & $25-86$ \\
\hline GGT $\left(\mathrm{U} \mathrm{L}^{-1}\right)$ & $0,2-64,4(21,4 \pm 18,3)$ & $0,2-77,7(16 \pm 18,9)$ & $0,1-50,5(12 \pm 14,3)$ & $0,5-9,5$ \\
\hline Colesterol (mg dL $\left.{ }^{-1}\right)$ & $32-374-(185,4 \pm 88)$ & $16-820(192,5 \pm 146,4)$ & $15-426 \pm 151,6 \pm 75,2)$ & $100-250$ \\
\hline Triglicerídeos (mg dL ${ }^{-1}$ ) & $30-360(122,5 \pm 72)$ & $6-1024(140,9 \pm 149,3)$ & $16-390(123,3 \pm 85,6)$ & $21-110$ \\
\hline Proteína total $\left(\mathrm{g} \mathrm{dL}^{-1}\right)$ & $3,5-13(6,6 \pm 2)$ & $2,6-14,5(6,2 \pm 2,5)$ & $1,1-10,9(6,7 \pm 2)$ & $5,0-8,0$ \\
\hline Albumina (g dL $\left.{ }^{-1}\right)$ & $0,7-3,1(1,8 \pm 0,6)$ & $0,5-3,5(1,8 \pm 0,8)$ & $0,6-7,9(2,3 \pm 1,6)$ & $2,2-3,6$ \\
\hline Globulinas ( $\mathrm{g} \mathrm{dL}^{-1}$ ) & $0,8-12(4,7 \pm 2,2)$ & $0,6-13,5(4,4 \pm 2,6)$ & $0,5-9(4,3 \pm 1,8)$ & $2,5-4,5$ \\
\hline Bil total (mg dL $\left.{ }^{-1}\right)$ & $0,3-19(3,9 \pm 6,3)$ & $0-28,6(3,7 \pm 6,3)$ & $0,1-14,8(1,5 \pm 3,6)$ & $0,05-0,5$ \\
\hline Bil direta (mg dL $\left.{ }^{-1}\right)$ & $0,2-14,5(2,7 \pm 4,9)$ & $0-19,3(2,1 \pm 3,9)$ & $0,1-11,6(0,9 \pm 2,7)$ & $0,0-0,2$ \\
\hline Bil indireta (mg dL ${ }^{-1}$ ) & $0,1-4,5(1,1 \pm 1,7)$ & $0-10(1,5 \pm 2,7)$ & $0-3,2(0,4 \pm 0,9)$ & $0,1-0,3$ \\
\hline
\end{tabular}


médios de 691,1U L L ${ }^{-1}$, enquanto que nos Grupos 2 e 3 os valores médios foram $646,4 \mathrm{U} \mathrm{L}^{-1}$ e $297,7 \mathrm{U} \mathrm{L}^{-1}$, respectivamente $(\mathrm{P}<0,042)$. Já em relação à bilirrubina direta, o valor médio foi de 2,7 $\mathrm{mg} \mathrm{dL}^{-1}$ (Grupo1), 2,1mg $\mathrm{dL}^{-1}$ (Grupo 2) e 0,9mg dL $\mathrm{m}^{-1}$ (Grupo 3) $(\mathrm{P}<0,004)$.

Uma clara relação $(\mathrm{P}<0,05)$ foi observada entre os títulos de anticorpos e a dosagem de FA e a bilirrubina direta. Entre os animais com títulos $\geq 200$, isto é, o somatório dos animais dos grupos 1 e 2, 87,5\% apresentavam elevação na FA e 54,5\% na bilirrubina direta. Já entre os animais negativos (Grupo 3), 40\% dos animais apresentavam alteração para a FA e 25\% na bilirrubina direta, o que pode ser explicado pela presença de sinais clínicos sugestivos, mesmo nos animais soronegativos, como icterícia. A causa da icterícia nos animais soronegativos, entretanto, não foi determinada. Alguns animais apresentaram dosagens normais destes parâmetros mesmo na presença de leptospirose aguda, sorologicamente confirmada. No Grupo 1, 24\% dos animais apresentaram FAnormal e 20\%, dosagens normais de bilirrubina direta. Já no Grupo 2, esses percentuais foram de 28,5 e 26,9\%, respectivamente. Assim sendo, considerou-se que, embora bastante freqüente, nem todos os animais reativos (títulos $=200$ ) apresentaram dano hepático significativo.

O comprometimento hepático evidenciado pelo aumento nos níveis séricos de parâmetros bioquímicos é achado freqüente nos casos de leptospirose canina aguda (HAGIWARA et al., 2004). Um achado digno de nota no presente estudo diz respeito à alteração não-significativa na atividade sérica das enzimas transaminases (ALT e AST). O aumento de atividade dessas enzimas é usualmente associado à lesão hepática, notadamente quando ocorre necrose de hepatócitos (LASSEN, 2004) e o aumento de atividade de AST em pacientes humanos com leptospirose aguda já foi descrita (CHANG et al., 2005). Em nosso estudo, a ausência de significativa alteração nesses parâmetros sugere a ausência de necrose hepatocelular na leptospirose canina.

Já a colestase é mais freqüentemente relatada na leptospirose aguda (NAVARRO et al., 1981), o que está de acordo com os achados do presente estudo, pois foi observada alteração significativa na atividade sérica da FA nos animais sorologicamente reativos em relação aos soronegativos. No entanto, a não-significância do aumento da atividade de GGT foi um achado inesperado, uma vez que esta enzima está frequentemente associada à ocorrência de colestase, embora seja considerada como um indicador menos sensível que a FA em caninos (LASSEN, 2004).

Conclui-se que existe uma clara correlação entre dano hepático, sem a ocorrência de necrose hepatocelular, com a sororeatividade específica para leptospirose em animais acometidos de infecção por amostras do sorogrupo Icterohaemorrhagiae.

\section{REFERÊNCIAS}

CHANG, M.L. et al. Disproportional exaggerated aspartate transaminase is a useful prognostic parameter in late leptospirosis. World Journal of Gastroenterology, v.11, n.35, p.5553-5556, 2005.

FAINE, S. et al. Leptospira and Leptospirosis. Austrália: Medsci, 2000. 272p.

FAVERO, A.C.M. et al. Sorovares de leptospiras predominantes em exames sorológicos de bubalinos, ovinos, caprinos, eqüinos, suínos e cães de diversos estados brasileiros. Ciência Rural, Santa Maria, v.32, n.4, p.613-619, 2002.

FREIRE, I.M.A. et al. Distribuição dos serovares de leptospira em caninos clinicamente suspeitos no Rio de Janeiro. Revista Brasileira de Ciência Veterinária, Rio de Janeiro, v.14, n.2, p.83-85, 2007.

FREIRE, I.M.A. et al. Níveis séricos de uréia e creatinina em cães com leptospirose aguda determinada por amostras do sorogrupo Icterohaemorrhagiae. Ciência Rural, Santa Maria, v.38, n.4, p.1172-1175, 2008.

GREENE, C.E. et al. Infectious diseases of the dog and cat. Athens: Saunders, 2006. 934p.

HAGIWARA, M.K.et al. Leptospirose canina. Vet News, v.11, p.7-8, 2004.

LASSEN, E.D. Laboratory evaluation of the liver. In: THRALL, M.A. Veterinary hematology and clinical chemistry. Philadelphia: Lippincott Williams \& Wilkins, 2004. Cap.23, p.355-377.

LILENBAUM, W. et al. Dosagem de uréia sanguínea em cães com leptospirose. Revista Brasileira de Medicina Veterinária, v.19, p.233-237, 1997.

NAVARRO, C.E.K. et al. Serum biochemical changes in dogs with experimental Leptospira Interrogans serovar Icterohaemorrhagiae infection. American Journal of Veterinary Research, v.42, p.1125-1129, 1981. 